\title{
Genotyping of F-RNA coliphages isolated from wastewater and river water samples
}

\author{
A Sundram ${ }^{1 *}, \mathbf{N}$ Jumanlal $^{1}$ and $M M$ Ehlers ${ }^{2}$ \\ ${ }^{1}$ Umgeni Water, PO Box 9, Pietermaritzburg 3200, South Africa \\ ${ }^{2}$ Department of Medical Virology, University of Pretoria/NHLS, Pretoria 0001, South Africa
}

\begin{abstract}
Faecal contamination of water sources can only be managed if the sources of pollution are identified and thus tools to distinguish between human and animal faecal sources are needed. Male-specific F-RNA coliphages have been classified into four sero-groups and evidence has been presented that two of these sero-groups are specific for human excreta and the other two for animal excreta. The sero-groups are readily detectable as genotypes with the application of molecular techniques, notable hybridisation tests using gene probes specific for each genotype. A standard ISO method was used for the detection of F-RNA coliphages. Wastewater containing predominantly animal excreta was collected from cattle, pig and chicken feedlots. Wastewater containing predominantly human excreta was collected from hospitals. The F-RNA genotyping study was qualitative and focussed on determining which groups of F-RNA phages were present in different wastewater and environmental samples. The results were in agreement with earlier reports on the specificity of F-RNA phage Genotypes 1 and 4 for animal wastes, and Genotypes 2 and 3 for human excreta. Besides being detected in human wastewater, F-RNA Group 3 was detected in both chicken and pig wastewater indicating that this Group was not specific to humans. The results showed that F-RNA phage Group 2 was the only group detected in seven of the twenty-six positive samples from the Dorpspruit, Slangspruit and uMsunduze Rivers, suggesting human faecal input. All other river water samples contained mixtures of F-RNA phage groups suggesting that the faecal input could not exclusively be ascribed to humans or animal sources alone. This suggested that both human and animal sources were responsible for contamination of receiving water at these sampling sites. The research proved that the genotyping of F-RNA phages was feasible in practice and could be used to assist in identifying the source of faecal pollution.
\end{abstract}

Keywords: genotyping, F-RNA phages, wastewater, river, human, cattle, pig, chicken, Groups $1-4$

\section{Introduction}

The direct discharge of domestic waste, leaching from poorly maintained septic tanks, and improper management of farm waste are suspected to be the major sources of water-borne diseases (Isobe et al., 2004). There is a greater health risk when humans are exposed to water polluted with human faeces, as opposed to animal faeces (Jagals et al., 1995; Scott et al., 2002). Information on the origin of faecal pollution is important because it gives an indication of the pathogens that may be expected, the risk of infection and the treatment that may be needed to control the transmission of the disease (Jagals et al., 1995; Sinton et al., 1998; Scott et al., 2002). It is now well known that the presence of F-RNA phages in a water sample generally indicates pollution by human or animal faeces (IAWPRC, 1991; DWAF, 1996; Leclerc, 2000; Schaper and Jofre, 2000).

The male-specific F-RNA phages have been classified into four groups on the basis of their serological and physiochemical properties including MS-2, f2, and JP501 in Group 1; GA, BZ13 and JP34 in Group 2; Q $\beta$, VK and TW18 in Group 3 and SP, F1 and TW28 in Group 4 (Havelaar and Hogeboom, 1984; Furuse, 1987; Beekwilder et al., 1996; Leclerc, 2000). These four groups of F-RNA phages have been fully characterised, with Groups 2 and 3 found to be highly associated with human

* To whom all correspondence should be addressed.

谓 +2733341 1342; fax: +2733 341 1501;

e-mail: Ashogan.Sundram@umgeni.co.za

Received 6 June 2005; accepted in revised form 7 November 2005. faecal contamination and Groups 1 and 4 more specific for animal contamination (Osawa et al., 1981; Havelaar et al., 1986; Furuse, 1987; Havelaar et al., 1990; Hsu et al., 1995; Sinton et al., 1998; Schaper and Jofre, 2000; Schaper et al., 2002; Scott et al., 2002; Cole et al., 2003). It has been reported that more than 90 to $95 \%$ of phages detected from sewage and environmental samples using Salmonella typhimurium (S. typhimurium) WG49 as the host, were F-RNA phages (Havelaar and Hogeboom, 1984; Debartolomeis and Cabelli, 1991; Hsu et al., 1995; Grabow et al., 1997; Uys 1999). In addition, S. typhimurium WG49 was successfully used for the detection of all four genotypes and was recommended for studying the presence and distribution of genotypes of F-RNA phages in environmental samples (Schaper and Jofre, 2000).

Researchers have successfully developed genotyping techniques to group the F-RNA phage isolates to help distinguish between faecal pollution of human or animal sources (Hsu et al., 1995; Beekwilder et al., 1996; Griffin et al., 2000). Hsu and coworkers (1995) indicated that highly specific nucleic acid probes for the detection of F-RNA phages could be used as an alternative to sero-typing.

Earlier research found that all isolates from animal faecal sources were grouped as Sero-Groups 1 and 4 with the exception of isolates from pig and piglet faeces which often contained Groups 2 and 3 F-RNA phages, suggesting that group classification would not always distinguish between human and porcine faecal contamination (Osawa et al., 1981; Furuse, 1987; Havelaar et al., 1990; Hsu et al., 1995; Cole et al., 2003). This occurrence could be explained by the dietary and living conditions of pigs, which have historically involved exposure to human faecal 
wastes (Hsu et al., 1995). These human-specific F-RNA phages introduced into pig populations have persisted because the gastrointestinal physiology and flora of pigs are similar to those of humans (Hsu et al., 1995).

The purpose of this study was to determine qualitatively the predominant F-RNA phage groups present in different wastewater and river water samples in an attempt to source faecal pollution to either human or animal origin. Male-specific F-RNA phages were isolated from different wastewater samples representative of different human and animal sources using the standard ISO methodology. The specificity of the gene probes using protocols optimised by earlier research was tested and F-RNA phages isolated in the positive control and river water samples were genotyped and grouped (Uys, 1999). This research aimed at distinguishing between the different genotypes of F-RNA phages present in wastewater and environmental samples in attempts to determine whether the pollution was of human or animal origin.

\section{Materials and methods}

\section{Sample collection}

Wastewater samples $(500 \mathrm{~m} \ell)$ representative of human faecal pollution were collected from two local hospitals in Pietermaritzburg. Wastewater $(500 \mathrm{~m} \ell)$ from a cattle feedlot in the Umgeni River catchment and wastewater from a piggery in the Pietermaritzburg midlands were collected as being representative of cattle and pig faecal pollution. Chicken wash and wastewater $(500 \mathrm{~m} \ell)$ from a poultry farm and abattoir in the Cato Ridge area was collected as representative of chicken faecal pollution. Samples $(500 \mathrm{~m} \ell)$ from the Baynespruit, Dorpspruit, Slangspruit and uMsunduze Rivers receiving runoff from informal settlements and informal farming around Pietermaritzburg were collected as representative environmental samples.

\section{Isolation of F-RNA phages}

The standard ISO-10705-1 (1995) double-layer agar technique, using S. typhimurium WG 49, was used to isolate F-RNA phages. The host culture was grown up to the log phase as described in ISO-10705-1 (1995), usually reached in 3 to $4 \mathrm{~h}$ when an absorbance of 0.76 was obtained at a wavelength of $560 \mathrm{~nm}\left(\mathrm{~A}_{560}\right)$. The growth rate was monitored closely using a spectrophotometer (Pharmacia LKB Ultraspec III) at $\mathrm{A}_{560}$. The host was stored on ice for a maximum of $2 \mathrm{~h}$. A $2.5 \mathrm{~m} \ell$ aliquot of top-agar containing $1 \%$ nalidixic acid (Sigma Aldrich) was pipetted into a test tube in a heating block (Bibby Stuart Scientific) and held at $48^{\circ} \mathrm{C}$. One millilitre of the host culture was added to the top-agar, followed by the addition of $1 \mathrm{~m} \ell$ of the test sample, or an appropriate dilution of the sample. The top-agar mixture was poured onto the bottom agar layer that had been pre-dispensed and set in a $90 \mathrm{~mm}$ Petri dish (Concorde Plastics). This procedure was carried out in triplicate. The plates were inverted before being incubated (Heraeus, SEPARATIONS SCIENTIFIC) overnight at $37 \pm 1^{\circ} \mathrm{C}$.

\section{Positive controls used to evaluate method efficiency and probe specificity}

The specificity of the probe is important for all genotyping experiments as non-specific probes could lead to cross-reactivity, and inevitably a misinterpretation of the results. Four representative positive control F-RNA coliphage strains, MS2 (Group I), GA (Group II), Q $\beta$ (Group III), and SP (Group IV) provided by the Department of Medical Virology (University of Pretoria, South Africa) were used as positive controls to test the efficiency of the methodology and specificity of the diluted probes. The positive control F-RNA phages were spotted onto Tryptone Yeast Extract Glucose Agar (Becton Dickinson) plates inoculated with host cultures of $S$. typhimurium $W G 49$ grown up to the $\log$ phase as established in earlier research (Uys, 1999). Following overnight incubation (Heraeus, SEPARATIONS SCIENTIFIC) at $37^{\circ} \mathrm{C}$, these positive F-RNA phage control spots developed into large areas of clearing of the lawn of host culture and not into individual plaques. This clearing of the bacterial lawn was representative of a positive phage:host interaction and was subjected to genotyping to test the efficiency of the genotyping technique together with the probe specificities.

\section{Transfer and fixation of F-RNA phage isolates}

Plates with typical F-RNA plaques or areas of clearing were placed in the cold room at $4^{\circ} \mathrm{C}$ for at least $30 \mathrm{~min}$. This was done to facilitate the transfer of phages by making the agar more solid and damp. Following recommendations by Uys (1999) who tested a range of suitable membranes, the phages were transferred onto Boehringer Mannheim (Roche Diagnostics) nylon membranes. The first membrane was adsorbed to the top layer for $1 \mathrm{~min}$. Up to four subsequent transfers could be obtained from one plate by increasing the time of adsorption to $2 \mathrm{~min}, 3.5$ min and 5 min respectively for every additional transfer. Four membranes were prepared for each set of isolates.

Following fixation of phages onto membranes, the phage RNA would have to be released and denatured, thereby exposing its bases to the complementary oligonucleotides (Beekwilder et al., 1996; Schaper and Jofre, 2000). The protocols for transfer and fixation of phages set up by Hsu et al. (1995) and Beekwilder et al. (1996) and adapted by Griffin et al. (2000) and Schaper and Jofre (2000) were followed. The membranes were placed in containers and submerged in $0.05 \mathrm{M} \mathrm{NaOH}$ (Saarchem) for $1 \mathrm{~min}$. The membranes were placed in clean containers and submerged in $0.1 \mathrm{M}$ sodium acetate (Saarchem) adjusted to $\mathrm{pH} 6$, for $30 \mathrm{~s}$. To allow fixation of the nucleic acid, the membranes were baked in an oven (Scientific, LABOTEC) at $80^{\circ} \mathrm{C}$ for $2 \mathrm{~h}$ as an alternative to using a UV trans-illuminator following the similar protocol used by Hsu et al. (1995) and Beekwilder et al. (1996).

\section{Pre-hybridisation}

Pre-hybridisation was conducted according to the method of Beekwilder et al. (1996) and modified by Uys (1999). This modification included increasing the pre-hybridisation time to $1 \mathrm{~h}$ resulting in reduced background (Uys, 1999). Each membrane was placed in hybridisation bags (Roche Diagnostics) with $5 \mathrm{m \ell}$ of pre-hybridisation solution (University of Pretoria, Medical Virology), containing 6 X Saline Sodium Citrate (SSC); 0.1\% Sodium Dodecyl Sulphate (SDS); 1 X Denhardt solution and $0.1 \mathrm{mg} \cdot \mathrm{m}^{-1}$ salmon sperm DNA (Invitrogen, USA). The salmon sperm DNA was denatured in a Perkin Elmer GeneAmp $2400 \mathrm{~T}$ thermocycler using a pre-set cycle of $99^{\circ} \mathrm{C}$ for $10 \mathrm{~min}$ thereafter held at $4^{\circ} \mathrm{C}$ until used. Hybridisation bags (Roche Diagnostics) were sealed and air bubbles minimized. The bags were placed at $37^{\circ} \mathrm{C}$ in a shaking waterbath (LABOTEC) at $100 \mathrm{r} \cdot \mathrm{min}^{-1}$ for $1 \mathrm{~h}$. 


\begin{tabular}{|l|l|}
\hline \multicolumn{3}{|c|}{ TABLE 1 } \\
Nucleotide sequences of oligomers used for probing F-RNA phages \\
(Beekwilder et al., 1996)
\end{tabular}

\section{Hybridisation}

To assist with chemi-luminescent detection, the probes (SigmaGenosys, Texas, USA) that were supplied (Table 1), were endlabelled with digoxigenin as recommended by Hsu et al. (1995) and Beekwilder et al. (1996). Following pre-hybridisation, the bags were carefully cut and $2.5 \mathrm{pmol} \cdot \mathrm{m}^{-1}$ of each of the digoxigenin-labelled probes (Sigma-Genosys) were added together with (50 to $100 \mu \ell)$ pre-hybridisation solution (excluding salmon sperm DNA). The hybridisation bags were resealed and placed back into the shaking water-bath (LABOTEC) held at $37^{\circ} \mathrm{C}$ at $100 \mathrm{r} \cdot \mathrm{min}^{-1}$ for $\pm 18 \mathrm{~h}$. The membranes were removed from the bags and placed in clean containers and washed twice in Buffer 1 containing 0.3 X SSC and $0.1 \%$ SDS, and placed for 15 min at $37^{\circ} \mathrm{C}$ in a shaking water-bath (LABOTEC) at $100 \mathrm{r} \cdot \mathrm{min}^{-1}$.

\section{Detection}

A DIG Wash and Block Buffer Set (Roche Diagnostics) containing washing, blocking and detection solutions was used. The membranes were placed in containers together with the washing buffer for $2 \mathrm{~min}$ at $37^{\circ} \mathrm{C}$. Each membrane was placed in a clean container together with $80 \mathrm{~m} \ell$ of Blocking Solution (Roche Diagnostics) for $15 \mathrm{~min}$ held at exactly $37^{\circ} \mathrm{C}$ in a shaking waterbath (LABOTEC) at $100 \mathrm{r} \cdot \mathrm{min}^{-1}$. Each membrane was incubated in $20 \mathrm{~m} \ell$ Blocking Solution (Roche Diagnostics) containing $1 \mu \ell$ of anti-digoxigenin-AP Fab fragments (Roche Diagnostics) for $30 \mathrm{~min}$ at room temperature $\left( \pm 22^{\circ} \mathrm{C}\right)$. The membranes were washed twice in the washing buffer (Roche Diagnostics) for $15 \mathrm{~min}$ at room temperature $\left( \pm 22^{\circ} \mathrm{C}\right)$. The membranes were placed in containers containing $20 \mathrm{~m} \ell$ detection buffer (Roche Diagnostics) agitated for $5 \mathrm{~min}$ at room temperature $\left( \pm 22^{\circ} \mathrm{C}\right)$. Fifty $\mathrm{m} \ell$ of the detection substrate, CPD-star (Roche Diagnostics) diluted 1:100 with the detection buffer, was dispensed onto the membranes in a clean container and allowed to react for 2.5 min at room temperature $\left( \pm 22^{\circ} \mathrm{C}\right)$. The damp membranes were sealed in new hybridisation bags with excess solution containing the CDP-Star (Roche Diagnostics) detection substrate. Membranes were placed in the Amersham hyper-cassette with Lumi film (Roche Diagnostics) placed over the membranes, under dark-room conditions. The cassette was sealed for 3.5 to $4 \mathrm{~min}$ followed by development of the Lumi film (Roche Diagnostics) using the appropriate developer and fixer solutions (Axim, Durban, South Africa) to generate dark circular spots representative of F-RNA phages from the various groups. Any dark spot obtained from a membrane treated with a specific probe, corresponding to a plaque on the original phage agar plate, was assigned to that respective F-RNA phage group.

\section{Results and discussion}

The isolation of F-RNA phages following the standard ISO10705-1 (1995) double-layer agar technique was simple and easy to follow. Plaques that developed were opaque and not as clear as those formed by typical somatic phages were. Due to the nature of some of the environmental samples, a fair amount of background bacterial growth did occur. The identification of organisms by nucleic acid hybridisation has clear advantages over other techniques in that it is genome-targeted and very specific and was relatively easy to perform once established.

\section{Evaluation of DNA:RNA hybridisation techniques us- ing control phages}

The hybridisation protocols established by Hsu et al. (1995) and Beekwilder et al. (1996) and optimised by Uys (1999) were carefully followed. The Hybond $\mathrm{N}+$ nylon membranes were most satisfactory and reproducibly yielded sharp plaque signals, contrasting clearly to a low background, even when plaques had a small diameter (Hsu et al., 1995; Beekwilder et al., 1996; Griffin et al., 2000; Schaper and Jofre, 2000). As researched by Hsu et al. (1995) and Beekwilder et al. (1996) and optimised by Uys (1999), overnight incubation of the viral nucleic acids with $2.5 \mathrm{pmol} \cdot \mathrm{m} \ell^{-1}$ of labelled probe at $37^{\circ} \mathrm{C}$ allowed maximum probe-target interaction and yielded good results when chemiluminescent detection was performed. Due to the lack of a UV trans-illuminator, initial experiments to fix phage RNA onto the membranes using a standard UV lamp $(365 \mathrm{~nm})$ placed over the membranes in a dark box proved unsuccessful. This was substituted with baking the membranes in a hot air oven at $80^{\circ} \mathrm{C}$ for $2 \mathrm{~h}$. The DNA: RNA hybrids appeared as dark spots on the X-Ray film (Fig. 1). Spots that developed were clearly visible and exposure time of 3.5 to $4 \mathrm{~min}$ was adequate in generating enough signals to allow detection on the film. Some background colour development did occur on some film whenever F-RNA phage plates were left in the cold room for longer periods, usually more than a week, allowing bacterial re-growth to occur.

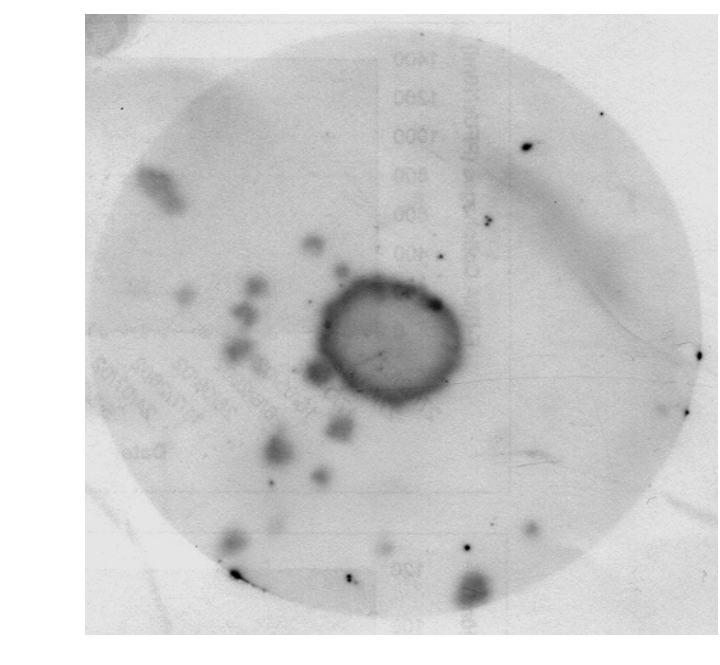

Figure 1

X-Ray Lumi-Film of a hybridised positive control F-RNA phage (MS 2) 


\begin{tabular}{|l|l|l|l|l|}
\hline \multicolumn{5}{|c|}{$\begin{array}{c}\text { TABLE 2 } \\
\text { Results obtained using known positive control } \\
\text { phages to test the efficiency of the DNA:RNA } \\
\text { hybridisation method and cross-reactivity of the } \\
\text { probes }\end{array}$} \\
\hline $\begin{array}{l}\text { Positive } \\
\text { Controls }\end{array}$ & Group I & Group II & Group III & Group IV \\
\hline MS2 & Positive & Negative & Negative & Negative \\
\hline GA & Negative & Positive & Negative & Negative \\
\hline Q $\beta$ & Negative & Negative & Positive & Negative \\
\hline SP & Negative & Negative & Negative & Positive \\
\hline
\end{tabular}

Researchers such as Hsu et al. (1995) and Beekwilder et al. (1996) developed probes for the four different subgroups of F-RNA phages by searching for stretches of 20 to 30 nucleotides, which showed complete conservation within one subgroup, while being absent from other subgroups. The F-RNA phages GA, SP, MS2 and Q $\beta$ representative of each of the four F-RNA phage groups were used as controls for the DNA: RNA hybridisation. These control phages confirmed that there was no cross-reactivity between probes of the different F-RNA phage genotypes as can be seen in Table 2 and identical results were obtained on repeating the experiment.

\section{Genotyping of F-RNA phages from wastewater and river samples}

Although both the Cabelli E. coli and Havelaar S. typhimurium WG 49 hosts detected other phages such as somatic and F-DNA phages, it was reported that more than 90 to $95 \%$ of phages detected from sewage and environmental samples using $S$. typhimurium WG 49 as the host, were F-RNA phages (Havelaar and Hogeboom, 1984; Debartolomeis and Cabelli, 1991; Hsu et al., 1995; Grabow et al., 1997). With this in mind it would be safe to assume that most of the phages isolated from the environmental samples using S. typhimurium WG 49 as the host were F-RNA phages, confirmed by the positive genotyping results obtained.

Sample sites representative of the predominant animal sources in the catchment viz. cattle, chicken and pigs were selected from accessible sites at abattoirs, feedlots and piggeries. Wastewater samples obtained from two private hospitals in Pietermaritzburg were selected as representative human faecal input. Samples were collected from these different sites and FRNA phages were isolated following the standard ISO-10705-1 (1995) methodology. These phages were hybridised with probes specific for each of the F-RNA phage Groups and detected using chemi-luminescent detection techniques as described earlier.

The results showed that F-RNA Groups 3 and 4 were the only two groups detected in pig wastewater (Table 3). Unlike previous studies conducted by Hsu et al. (1995), F-RNA phage Group 2 was not detected in the pig wastewater tested. Another interesting finding was that F-RNA phage Groups 1 and 4 were detected along with Group 3 in the chicken wastewater. Previously, Groups 2 and 3 were found to be more specific to humans and by exception in pigs that were considered to have a similar gastrointestinal physiology and flora to humans partly because of the close living conditions (Hsu et al., 1995; Schaper et al., 2002; Cole et al., 2003). It was therefore unusual that F-RNA phage Group 3 was detected in chicken wastewater on two separate occasions. It is likely that farming activities on the chicken farms could have contributed to human input in the chicken wastewater that was possibly not exclusively chicken waste. The results indicated the specificity of Groups 2 and 3 for humans,

\begin{tabular}{|l|l|l|}
\hline \multicolumn{3}{|c|}{$\begin{array}{c}\text { MABLE 3 } \\
\text { isolated from different wastewater samples }\end{array}$} \\
\hline Date & Sample description & $\begin{array}{l}\text { F-RNA phage } \\
\text { groups detected }\end{array}$ \\
\hline $27 / 06 / 02$ & Pig wastewater & Groups 3 and 4 \\
\hline $22 / 12 / 02$ & Pig wastewater & Groups 3 and 4 \\
\hline $24 / 12 / 02$ & Pig wastewater & Group 4 \\
\hline $06 / 01 / 03$ & Pig wastewater & Group 3 \\
\hline $06 / 01 / 03$ & Pig wastewater & Groups 3 and 4 \\
\hline $17 / 07 / 02$ & Chicken wastewater & Groups 1,3 and 4 \\
\hline $27 / 11 / 02$ & Chicken wastewater & Groups 3 and 4 \\
\hline $31 / 12 / 02$ & Chicken wastewater & Group 4 \\
\hline $02 / 07 / 02$ & Cattle feedlot & Group 1 \\
\hline $06 / 01 / 03$ & Cattle feedlot & Groups 1 and 4 \\
\hline $06 / 01 / 03$ & Cattle feedlot & Groups 1 and 4 \\
\hline $02 / 09 / 02$ & Hospital wastewater discharge & Group 2 \\
\hline $04 / 10 / 02$ & Hospital wastewater discharge & Group 3 \\
\hline $29 / 11 / 02$ & Hospital wastewater discharge & Group 2 and 3 \\
\hline $06 / 01 / 03$ & Hospital wastewater discharge & Group 3 \\
\hline
\end{tabular}

as these were the only two F-RNA phage groups detected in all four of the hospital wastewater samples.

River sites in the Pietermaritzburg catchment were selected on historical E. coli data indicating faecal pollution. Samples from the Baynspruit, Dorpspruit, Slangspruit and uMsunduze rivers were taken between the summer periods of October 2002 and February 2003. The F-RNA analyses were conducted on samples when E. coli counts exceeded $10000 \cdot 100 \mathrm{~m}^{-1}$ resulting from various faecal inputs. These faecal inputs ranged from the faeces of grazing animals to broken and overflowing blocked sewers and informal sanitation often reaching water sources following heavy rainfall events.

All four F-RNA phage genotypes were detected in the river samples analysed (Table 4). The plaques were detected as dark circular spots on the X-ray Lumi film and varied in size from small to large as seen in Fig. 2. The background colour development was possibly due to a combination of background bacterial growth, inadequate washing, poor handling of the Lumi film and over-exposure. There were instances where poor development of the DNA: RNA hybrids occurred on the film, and these membranes were subsequently exposed to the Lumi film for longer periods and this over-exposure was sometimes unavoidable.

In addition, plaques were obtained from selected river water samples, harvested and spotted onto specific areas of tryptone yeast extract glucose agar plates to determine the F-RNA phage genotypes present. Up to 5 environmental samples could be analysed per tryptone yeast extract glucose agar plate, saving time and making the genotyping assay for multiple environmental samples more cost-effective.

The Slangspruit River, situated close to an informal settlement in Pietermaritburg, often receives faecal input from runoff and poor sanitation infrastructure unable to contain human sewage. The human faecal input is evident by the detection of F-RNA phage Groups 2 and 3 in all samples. Groups 1 and 4 were also detected indicating the presence of animal faecal excrement. Groups 1 and 3 were the only F-RNA phage groups present in samples from 3 different sites on the Baynespruit River sampled on the 23/1/03 whilst all 4 groups were detected from samples taken from the Baynespruit River on other days. This river runs through an industrial area with some cattle graz- 


\begin{tabular}{|c|c|c|}
\hline \multicolumn{3}{|c|}{$\begin{array}{l}\text { TABLE } 4 \\
\text { Molecular characterisation of F-RNA phages } \\
\text { isolated from different river water samples }\end{array}$} \\
\hline Date & River & $\begin{array}{l}\text { F-RNA phage } \\
\text { groups detected }\end{array}$ \\
\hline $17 / 10 / 02$ & Slangspruit & 1,2 and 3 \\
\hline $28 / 10 / 02$ & Slangspruit & 2 \\
\hline $15 / 01 / 03$ & Slangspruit & 1,2 and 3 \\
\hline $28 / 02 / 03$ & Slangspruit & 1,3 and 4 \\
\hline $23 / 01 / 03$ & Baynespruit-Site 1 & 1 and 3 \\
\hline $23 / 01 / 03$ & Baynespruit - Site 2 & 1 and 3 \\
\hline $23 / 01 / 03$ & Baynespruit - Site 3 & 1 and 3 \\
\hline $06 / 02 / 03$ & Baynespruit-Site 1 & $1,2,3$ and 4 \\
\hline $06 / 02 / 03$ & Baynespruit - Site 2 & $1,2,3$ and 4 \\
\hline $13 / 02 / 03$ & Baynespruit & 2,3 and 4 \\
\hline $28 / 02 / 03$ & Baynespruit-Site 1 & None \\
\hline $28 / 02 / 03$ & Baynespruit - Site 2 & 1,2 and 3 \\
\hline $23 / 01 / 03$ & Dorpspruit & 1 and 3 \\
\hline $06 / 02 / 03$ & Dorpspruit & 2 \\
\hline $13 / 02 / 03$ & Dorpspruit & 1,3 and 4 \\
\hline $13 / 02 / 03$ & Dorpspruit & 1 \\
\hline $23 / 01 / 03$ & uMsunduze & 1 and 3 \\
\hline $06 / 02 / 03$ & uMsunduze & 1,2 and 3 \\
\hline $06 / 02 / 03$ & uMsunduze & 2 \\
\hline $13 / 02 / 03$ & uMsunduze & $1,2,3$ and 4 \\
\hline $13 / 02 / 03$ & uMsunduze & 2 and 3 \\
\hline $13 / 02 / 03$ & uMsunduze & 2 \\
\hline $13 / 02 / 03$ & uMsunduze & 2 \\
\hline $28 / 02 / 03$ & uMsunduze & 2 \\
\hline $28 / 02 / 03$ & uMsunduze & 2 \\
\hline $28 / 02 / 03$ & uMsunduze & 1,3 and 4 \\
\hline
\end{tabular}

ing and domesticated animals including chickens present in informal settlements. This river often receives faecal input from these sources and the results suggested that both human and animal sources were responsible for the faecal pollution. A similar picture presented in the Dorpspruit River that meanders along the city of Pietermaritburg, even passing horse stables before confluence with the uMsunduze River. The uMsunduze River that flows through the upper Pietermaritzburg catchment, eventually joins the Umgeni River, receives faecal input from run-off of various animals ranging from cattle and chickens to human faecal matter originating from broken and blocked sewers and informal settlements. Samples taken from various points along the uMsunduze River indicated that there were many instances $(n=6)$ where only Groups 2 and 3 were detected suggesting that the main source of faecal pollution in these samples was of human origin. Despite being time consuming and expensive, this technique could be used to help distinguish between human and animal faecal pollution in environmental samples.

\section{Conclusions}

The study was conclusive in proving that genotyping of F-RNA phages using chemi-luminescent detection techniques was easy to perform producing results that were easy to interpret. The use of a hot-air oven thermostatically controlled at $80^{\circ} \mathrm{C}$ was successful in fixing the viral RNA onto the positively charged membranes due to the lack of a UV trans-illuminator. The least amount of background development on the X-ray film was

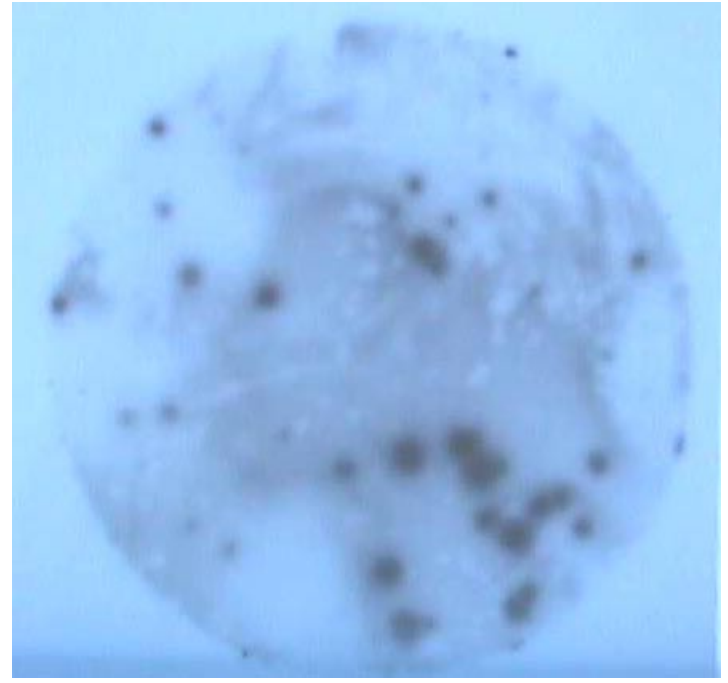

Figure 2

$X$-Ray Lumi-film of DNA:RNA hybrids of F-RNA phages isolated in a river water sample

achieved when plaques were transferred before any re-growth of bacteria occurred on plates stored in the cold room (4 to $10^{\circ} \mathrm{C}$ ). The probes selected for the hybridisation were sensitive and no cross-reactivity between the four F-RNA phages groups occurred.

The results confirmed earlier reports on the specificity of F-RNA phage Genotypes 1 and 4 for animal wastes, and Genotypes 2 and 3 for human excreta, in a part of the world where not much research in this particular field has been done previously (Havelaar et al., 1986). Male-specific F-RNA phage Group 3 was detected in both chicken and pig wastewater indicating that this group may not be specific to humans. There is a possibility that the chicken wastewater could have been contaminated with human faecal input due to farming activities. The major sources of faecal contamination in river water samples were not established in most instances as all four groups were detected in river water samples. The rivers that were surveyed were influenced by human and animal activities and genotyping used in isolation was not sufficient in determining which of these sources had more impact. There would appear to be an abundance of F-RNA phage Genotypes 1 and 2 in the environmental samples, possibly due to their resistance to the prevailing environmental conditions. This research suggested that the results of F-RNA phage genotyping of F-RNA phages isolated from river water samples needs to be used together with other discriminating microbiological or chemical analyses to be more conclusive in establishing whether faecal input was of human or animal origin. Information on the human or animal origin of faecal pollution is important because it gives an indication of the possible risk of infection and the possible water treatment that may be needed to control the transmission of potential waterborne diseases.

\section{Acknowledgements}

The researchers would like to thank Mrs A Vrey of the Department of Medical Virology, University of Pretoria for her technical assistance with the genotyping experiments. The research assistance by Miss N Jumanlal of Umgeni Water is greatly appreciated. Umgeni Water is gratefully acknowledged for the financial support of this study. 


\section{References}

BEEKWILDER J, NIEUWENHUIZEN R, HAVELAAR AH and VAN DUIN J (1996) An oligonucleotide hybridisation assay for the identification and enumeration of F-specific RNA phages in surface water. J. Appl. Bacteriol. 80 179-186.

COLED, LONG SC and SOBSEY MD (2003) Evaluation of F+RNA and DNA coliphages as source-specific indicators of fecal contamination in surface waters. Appl. Environ. Microbiol. 69 6507-6514.

DEBARTOLOMEIS J and CABELLIV J (1991) Evaluation of an Escherichia coli host strain for enumeration of $\mathrm{F}$ male-specific bacteriophages. Appl. Environ. Microbiol. 57 1301-1305.

DEPARTMENT OF WATER AFFAIRS AND FORESTRY (DWAF) - HOLMES S [ed.] (1996) South African Water Quality Guidelines: Domestic Use 1 89-90.

GRABOW WOK, VREY A, UYS M and DE VILLIERS JC (1997) Evaluation of the Application of Bacteriophages as Indicators of Water Quality. South African Water Research Commission. Report No 540/1/98.

GRIFFIN DW, STOKES R, ROSE JB and PAUL JH (2000) Bacterial indicator occurrence and the use of an $\mathrm{F}^{+}$specific RNA coliphage assay to identify fecal sources in Homosassa Springs, Florida. Microb. Ecol. 39 56-64.

FURUSE K (1987) Distribution of coliphages in the environment: general considerations. In: Goyal SM, Gerba CP and Bitton $\mathrm{G}$ (eds.) Phage Ecology. Wiley-Interscience, New York. 87-124.

HAVELAARAH and HOGEBOOM WM (1984) A method for enumeration of male-specific bacteriophages in sewage. J. Appl. Bacteriol. 56 439-447.

HAVELAAR AH, FURUSE K and HOGEBOOM WM (1986) Bacteriophages and indicator bacteria in human and animal faeces. J. Appl. Bacteriol. 60 255-262.

HAVELAAR AH, POT-HOGEBOOM WM, FURUSE K, POT R and HORMANN MP (1990) F-Specific RNA bacteriophages and sensitive host strains in faeces and wastewater of human and animal origin. J. Appl. Bacteriol. 69 30-37.

HSU FC, SHIEH YSC, VAN DUIN J, BEEKWILDER MJ and SOBSEY MD (1995) Genotyping male-specific RNA coliphages by hybridi- sation with oligonucleotide probes. Appl. Environ. Microbiol. 61 3960-3966.

ISO 10705-1 (1995) Water Quality - Detection and Enumeration of Bacteriophages - Part 1, Enumeration of F-Specific RNA Bacteriophages. International Organisation for Standardisation.

ISOBE KO, TARAO M, CHIEM NH, MINH LY and TAKADA H (2004) Effect of environmental factors on the relationship between concentrations of coprostanol and fecal indicator bacteria in tropical (Mekong Delta) and temperate (Tokyo) freshwaters. Appl. Environ. Microbiol. 70 814-821.

INTERNATIONAL ASSOCIATION FOR WATER POLLUTION RESEARCH AND CONTROL (IAWPRC) (1991) Study Group on Health-Related Water Microbiology. (AH Havelaar (ed.)) Bacteriophages as model viruses in water quality control. Water Res. 25 529-545.

JAGALS P, GRABOW WOK and DE VILLIERS JC (1995) Evaluation of indicators for assessment of human and animal faecal pollution of surface runoff. Water Sci. Technol. 31 235-241.

LECLERC H, EDBERG S, PIERZO V and DELATTRE JM (2000) Bacteriophages as indicators of enteric viruses and public health risk in groundwaters. J. Appl. Microbiol. 88 5-21.

GRIFFIN DW, STOKES R, ROSE JB and PAUL JH (2000) Bacterial indicator occurrence and the use of an $\mathrm{F}^{+}$specific RNA coliphage assay to identify fecal sources in Homosassa Springs, Florida. Microb. Ecol. 39 56-64.

OSAWA S, FURUSE K and WATANABE I (1981) Distribution of ribonucleic acid coliphages in animals. Appl. Environ. Microbiol. 41 164-168.

SCHAPER M and JOFRE J (2000) Comparison of methods for detecting genotypes of F-specific RNA bacteriophages and fingerprinting the origin of faecal pollution in water samples. J. Virol. Meth. 89 $1-10$.

SCHAPERM, JOFRE J, UYS M and GRABOW WOK (2002) Distribution of genotypes of F-specific RNA bacteriophages in human and non-human sources of faecal pollution in South Africa and Spain. J. Appl. Microbiol. 92 657-667.

SCOTT TM, ROSE JB, JENKINS TM, FARRAH SR and LUKASIK J (2002) Microbial source tracking: Current methodology and future directions. Appl. Environ. Microbiol. 68 5796-5803. 